\title{
Identidade narrativa e bem-estar em jovens em situação de vulnerabilidade
}

\author{
Narrative identity and well-being in vulnerable youth \\ Identidad narrativa y bienestar en jóvenes vulnerables
}

\section{Resumo}

A Psicologia Narrativa surgiu a partir da necessidade de investigar o papel da linguagem na construção do sujeito psicológico. As narrativas biográficas têm o papel de dar sentido às experiências com o mundo e de construir nossa identidade. É, portanto, fundamental para o estabelecimento de uma personalidade equilibrada a forma como as pessoas organizam os eventos de vida e os significam em uma narrativa. No presente trabalho investigamos a construção narrativa da identidade em adolescentes que passaram por situações de vulnerabilidade. Estudamos a produção de narrativas autobiográficas, investigando e buscam construir resiliência e bem-estar. Este trabalho foi desenhado como um estudo de casos múltiplos. Participaram do estudo três adolescentes de ambos os sexos, com idade entre 13 e 16 anos. Os jovens participaram de uma entrevista individual com aplicação do protocolo de Entrevista de Elicitação da Narrativa de Vida. As narrativas foram analisadas a partir da abordagem da Matriz Narrativa, de Gonçalves, Henriques e colaboradores. Os indicadores de bem-estar foram discutidos com os Big Three, de McLean e colaboradores. As histórias de vida mostraram diferentes maneiras de lidar com o sofrimento e de buscar superação das dificuldades apresentadas pela vida. A construção narrativa de bem-estar em meio às dificuldades foi verificada a partir de um entrelaçamento das três dimensões de organização estrutural, autobiographical reasoning e elementos motivacionais e afetivos. Foi observado um balanceamento entre os elementos narrativos com a finalidade de construção de uma história organizada e de uma personalidade equilibrada.

Palavras-chave: Identidade narrativa; Psicologia narrativa; Adolescência; Vulnerabilidade; Bem-estar.

\begin{abstract}
Narrative Psychology aroused from research about the role of language on construction of psychological subjectivity. Biographical narratives help people to make sense on his experiences with the world and on building his identity. The way people organize life events and signify them in a narrative is fundamental to the establishment of a balanced personality. In the present work, we study the narrative construction of identity in adolescents in vulnerability situation. We seek the production of autobiographical narratives in search of construction of resilience and well-being. This work was designed as a multiple case study. Three adolescents of both sexes, aged between 13 and 16 years, participated in the study. They had an individual interview with the application of the Life Narrative Elicitation Interview protocol. The narratives were analyzed using the Narrative Matrix, by Gonçalves, Henriques and collaborators. Well-being indicators were discussed with the Big Three proposed by McLean and collaborators. Life stories showed different ways of dealing with suffering and seeking to overcome the difficulties in life. Narrative construction of well-being in the midst of difficulties was verified from an intertwining of the three dimensions of structural organization, autobiographical reasoning and motivational and affective elements. A balance was observed between the narrative elements in order to build an organized story and a balanced personality.
\end{abstract}

Keywords: Narrative identity; Narrative psychology; Adolescence; Vulnerability; Well-being.

\section{Resumen}

La Psicología Narrativa surge de la necesidad de investigar el papel del lenguaje en la construcción del sujeto psicológico. Las narrativas biográficas tienen el papel de dar sentido a las experiencias con el mundo y de construir nuestra identidad. Por lo tanto, es fundamental para el establecimiento de una personalidad equilibrada cómo las 
personas organizan los eventos de la vida y los significan en una narrativa. En el presente trabajo investigamos la construcción narrativa de la identidad en adolescentes que han pasado por situaciones de vulnerabilidad. Estudiamos la producción de narrativas autobiográficas, investigando cómo estos jóvenes buscan construir resiliencia y bienestar. Este trabajo fue diseñado como un estudio de caso múltiple. En el estudio participaron tres adolescentes de ambos sexos, con edades comprendidas entre los 13 y los 16 años. Los jóvenes participaron de una entrevista individual con la aplicación del protocolo Life Narrative Elicitation Interview. Las narrativas fueron analizadas utilizando el enfoque de Matriz Narrativa, por Gonçalves, Henriques y colaboradores. Los indicadores de bienestar fueron discutidos con los Big Three, por McLean y colaboradores. Las historias de vida mostraron diferentes formas de afrontar el sufrimiento y buscar superar las dificultades que presenta la vida. La construcción narrativa del bienestar en medio de las dificultades se verificó a partir de un entrelazamiento de las tres dimensiones de organización estructural, autobiographical reasoning y elementos motivacionales y afectivos. Se observó un equilibrio entre los elementos narrativos para construir una historia organizada y una personalidad equilibrada.

Palabras clave: Identidad narrativa; Psicología narrativa; Adolescencia; Vulnerabilidad; Bienestar.

\section{Introdução}

\section{Psicologia Narrativa e Identidade}

A Psicologia Narrativa surgiu a partir da necessidade de investigar o papel da linguagem, associada à história e à cultura na construção do sujeito psicológico. A narrativa aglutina esses três elementos em histórias ficcionais ou não ficcionais, que têm um papel de dar sentido à nossa experiência com o mundo (Sarbin, 1986). Tendemos a organizar as situações vividas narrativamente em uma sequência temporal e/ou lógica, o que além de nos proporcionar uma inteligibilidade sobre o que aconteceu, também permite a transmissão da experiência de maneira que ela seja compreensível. Além disso, aglutinamos a essa narrativa elementos de nosso passado, que atuam como referência na interpretação e entendimento das novas experiências. A esses elementos se somam as narrativas que conhecemos: histórias de amigos, de livros e filmes que também nos auxiliam na organização e entendimento das experiências vividas. É em função disso que Bruner (1987) propõe a narrativa como um kit de ferramentas com o qual organizamos e damos sentido ao mundo e à vida.

Mais do que organizar nossa experiência e dar sentido à realidade, a narrativa também organiza nossa interioridade e identidade (Bruner, 1991; Hermans \& Kempen, 1993). A noção de que a identidade e o self são construídos em uma negociação de significados entre o sujeito e o mundo nos leva a uma dessubstancialização desses conceitos, que tornam-se construções narrativas (László, Ehmann, Pólya \& Péley, 2007). Assim, Hermans (2008), na teoria do Self Dialógico, concebe a identidade como um diálogo interior entre diferentes vozes, que representam as diversas posições socioculturais com as quais a pessoa tem de lidar e às quais ela interioriza ao longo do processo de desenvolvimento psicológico. Segundo Hermans, nosso mundo interior está pleno de figuras midiáticas, réplicas imaginárias de amores, parentes ou amigos, bem como figuras extraídas de sonhos e outras fantasias, com as quais mantemos diálogos imaginários. Esses diálogos imaginários são o próprio processo de significação da nossa experiência com o mundo, mas também o de construção e de manutenção de nossa identidade. As vozes/posições relacionam-se umas com as outras, tal como personagens em uma novela polifônica, resultando em um self complexo e narrativamente estruturado (Vieira \& Henriques, 2014).

A construção da identidade também envolve uma dimensão temporal, a qual se organiza através da história de vida da pessoa, não como ela ocorreu literalmente, mas como ela é narrada atualmente (McAdams, 2001; Fivush, 2008). Para McAdams, a capacidade para a construção de uma história de vida é um marco no processo de aquisição de uma identidade psicossocial madura. A adolescência é o momento no qual convergem as habilidades cognitivas desenvolvidas ao longo da infância para organizar uma narrativa autobiográfica coerente e as exigências socioculturais para um posicionamento dentro da sociedade (Habermas, Ehlert-Lerche \& de Silveira, 2009). Esse processo culmina na necessidade de construção de uma identidade socioculturalmente situada. A identidade organiza-se na forma de uma narrativa autobiográfica. Essa narrativa tem a função de construir unidade e propósito à vida e de dar sentido ao mundo. As histórias de vida são co-construídas com as 
outras pessoas e com o contexto sociocultural. Elas têm a capacidade de integrar diacronicamente os diferentes episódios e situações de vida em histórias carregadas de sentido. Elas têm também a capacidade de organizar as crenças e posicionamentos diante da vida em termos de um processo de mudança e transformação (McLean, Pasupathi \& Pals, 2007). As histórias de vida têm, portanto, uma função integradora, organizando os diferentes papéis sociais, as diversas formas de relacionamento, os sentimentos e pensamentos, de maneira que eles possam ser entendidos como partes de uma mesma configuração. Mas a identidade não é algo que emerge na adolescência como acabada, pelo contrário, ela está sempre sendo construída e reconstruída. Ela pode ser entendida como uma narrativa aberta, nunca totalmente concluída, ou como uma antologia de histórias mais ou menos integradas e coerentes acerca da vida de uma pessoa. O caráter comum a essas narrativas é sua tendência à unidade e à coerência.

\section{Identidade Narrativa, Bem-Estar e Resiliência}

As histórias que contamos sobre nós mesmos não apenas nos revelam, como nos constroem e nos sustentam ao longo do tempo. É, portanto, fundamental para a construção e manutenção de uma personalidade equilibrada, não apenas o que ocorreu ao longo da vida, mas a forma através da qual a pessoa organizou os eventos e os significou em uma narrativa (McLean, Syed, Pasupathi, Adler, Dunlop, Drustrup, Fivush, Graci, Lilgendahl, Lodi-Smith, McAdams, \& McCoy, 2019). A questão da construção de uma identidade que, através de uma resiliência às dificuldades impostas pela vida, consegue manter um estado de bem-estar tem sido tema de estudo frequente entre os investigadores da narrativa (Fitzhardinge, 2008; McAdams \& McLean, 2013; Adler, Lodi-Smith, Philippe, \& Houle, 2016; McLean et al., 2019).

O significativo trabalho de McLean et al. (2019) com 855 participantes e 2.565 histórias de vida definiu como elementos centrais das narrativas capazes de produzir bem-estar a presença de uma estrutura narrativa organizada, de uma reflexão sobre si próprio (autobiographical reasoning) e de temas motivacionais e afetivos. O que foi por eles denominado the initial Big Three. Em uma estrutura narrativa, o sujeito consegue organizar os eventos em uma sequência cronológica coerente, construindo também uma coerência entre o que aconteceu com ele e o contexto. Em um movimento auto reflexivo, o sujeito é capaz de explorar as diferentes situações de vida, refletindo sobre elas tanto em uma abordagem acomodativa como em uma assimilativa. A abordagem acomodativa requer da pessoa uma revisão significativa da própria história e a criação de novas narrativas capazes de dar conta dos novos significados ou das novas experiências. Na abordagem assimilativa o sujeito organiza as novas experiências, situando-as nos temas e nas narrativas já canônicas a seu entendimento da vida. Através do autobiographical reasoning a pessoa reflete sobre seu processo de mudança e crescimento, transformando em aprendizagem as experiências difíceis. O terceiro elemento dos Big Three é a presença de temas afetivos e motivacionais. Os temas afetivos da narrativa são estudados através da tonalidade afetiva da história como um todo, ou da trajetória da narrativa, via movimentos de redenção (passagem de um estado negativo para um positivo) ou de contaminação (passagem de um estado positivo para um negativo). Já os componentes motivacionais da narrativa procuram captar a orientação geral da história de vida em termos da agência (agency) ou da comunhão (communion). Na agência o elemento motivacional é o da afirmação de si mesmo, através da autonomia ou da necessidade de influenciar o meio ou as outras pessoas. Na comunhão a motivação está centrada no estabelecimento e manutenção de relações afetivas e interpessoais. A presença de elementos afetivos já é por si só um fator protetor da personalidade. Quando a valência é positiva, como no caso de uma tonalidade afetiva otimista, de um movimento narrativo de redenção ou da ligação bem sucedida às outras pessoas, a tendência é o aumento do estado de bem-estar (McLean et al., 2019).

No presente trabalho investigamos a construção narrativa da identidade em adolescentes que passaram por situações de vulnerabilidade psicossocial. Estudamos a produção de narrativas autobiográficas, olhando para a forma como os 
adolescentes lidaram com as situações adversas em suas vidas e buscando os processos envolvidos na construção de resiliência e bem-estar.

\section{Metodologia}

\section{Delineamento}

Este trabalho foi desenhado como um estudo de casos múltiplos, segundo o modelo de Yin (2001). Cada caso é, assim, apresentado e analisado individualmente para passar, em um segundo momento, por uma discussão integrativa com os outros casos e com a literatura.

\section{Participantes}

Participaram deste estudo 3 adolescentes de ambos os sexos, com idade entre 13 e 16 anos, em situações de vulnerabilidade, tais como convivência em ambiente com risco de violência e abuso de substâncias ilícitas, situações de negligência, divórcio, violência familiar, suicídio e bullying. Os participantes do estudo são alunos de uma escola municipal de uma cidade da região metropolitana de Porto Alegre, localizada em um bairro da periferia com alto índice de violência e presença de tráfico de drogas.

\section{Procedimentos}

A escola se encarregou de indicar os jovens, fazer contato com as famílias e encaminhar os Termos de Consentimento Livre e Esclarecido e de Assentimento Livre e Esclarecido. Após a assinatura, os jovens foram convidados a participar de uma entrevista individual com aplicação do protocolo de Entrevista de Elicitação da Narrativa de Vida (Gonçalves, Henriques \& Vieira, 2010). As entrevistas foram gravadas e a seguir, transcritas. Este trabalho foi aprovado pelo Comitê de Ética em Pesquisa da Universidade Luterana do Brasil (CEP/ ULBRA): CAAE nº 57935316.7.0000.5349.

\section{Análise de dados}

Após a transcrição das entrevistas, procedeu-se à analise da narrativa. Em uma primeira leitura verificou-se a presença de narrativa. Uma narrativa é definida por elementos de orientação, ação, resultado e/ou avaliação. Em uma segunda leitura as narrativas foram divididas em sequências (Sn1, Sn2 ...), seguindo uma organização em episódios temáticos. Em uma terceira leitura foram analisados os elementos narrativos de cada sequência, segundo a abordagem da Matriz Narrativa de Gonçalves, Henriques e colaboradores (2006a, 2006b, 2006c). Avaliamos aqui a estrutura narrativa, o conteúdo narrativo (personagens, cenários, ações e temas) e o processo narrativo (expressão de percepções, sentimentos, idéias e reflexões).

\section{Resultados}

\section{Caso Sofia}

Sofia é uma jovem de 13 anos de idade. Seus pais se separaram quando ela era bebê. Atualmente mora com a mãe. Sofia construiu uma história de vida em quatro episódios, com os temas ano novo na praia, relação com o pai, reunião do CLJ com os pais, relação conflituosa do pai com a família materna.

No primeiro episódio, através do relato de um dia marcante, ela traz o conflito familiar mais significativo em sua forma exemplar. Um dia marcante em sua vida foi um ano novo que passou com seu pai. Estava com a família paterna em um condomínio na praia. O pai tem o hábito de beber e estava alcoolizado, tendo agredido a madrasta e criado um ambiente de conflito que se estendeu até a madrugada. "Então ele foi à beira da praia, que não é tão longe e puxou os cabelos da minha 
madrasta e toda minha família ficou até às quatro da manhã brigando, ele queria empurrar minha madrasta da janela. Aquele dia foi muito ruim, foi horrível" (Sofia, 13 anos).

Nos episódios seguintes ela traz outros exemplos desse conflito não resolvido em sua história de vida. Como no segundo, em que fala sobre a relação com o pai, ilustrando-a com a narrativa da cirurgia, na qual o pai a foi visitar e a buscou no hospital. "Minha relação com meu pai é boa, ele me liga. Até há duas semanas atrás eu fiz uma cirurgia, ele me visitou, me buscou no hospital" (Sofia, 13 anos).

No terceiro episódio, Sofia conta que gosta muito de ir à igreja e que se sente bem lá. Certa vez, em uma reunião para os pais do CLJ, convidou seu pai para acompanhá-la, mas ele recusou por ser ateu. "Eu comecei a chorar porque só foi umas três pessoas sem pai, mas um não foi porque estava trabalhando. (...) Eu pedi para ele ir, expliquei que não seria dentro da igreja, era em uma salinha, e eu gosto, me sinto bem lá, mas ele disse que não iria, a gente já brigou bastante por isso. A nossa relação é tranquila, só que ele implica bastante com isso" (Sofia, 13 anos).

No quarto episódio, Sofia ainda discorre sobre os conflitos do pai com a família materna, onde eles se falam bem pouco e que raramente ele vai a sua casa. No ano anterior ele não pagava pensão alimentícia, o que gerou uma cobrança judicial e atualmente ele paga. "Esta tudo bem, mas eles se falam bem pouco. Até quando ele vai a minha casa, o que é raro, eles se olham, se falam um pouco" (Sofia, 13 anos).

Sofia fecha a narrativa com uma reflexão sobre sua história. Pensa que brigas não levam a nada, que ela valoriza muito a família e espera uma vida melhor para si. "Dai acho que a gente não precisa ficar brigando, somos família. (...) Hoje eu espero uma vida melhor pra mim, mais do que isso, é ruim passar por tudo isso, temos que levar coisas boas e não mágoas" (Sofia, 13 anos).

Sofia não constrói uma narrativa de vida cronologicamente situada, mas emocionalmente situada, na qual os eventos mais carregados de afeto têm primazia em relação aos eventos temporalmente dispostos em uma ordem cronológica. A narrativa aparece, entretanto, bem estruturada, orientando o leitor acerca do tempo e espaço, das ações que os personagens desenvolvem e seus desfechos. Ao final da história, traz uma avaliação, na qual reflete sobre o que aprendeu com ela. Neste caso, encontramos o nó da narrativa, uma complicação da sua história de vida no conflito com o pai. Esse conflito não encontra-se resolvido, de maneira que o nó não é desatado e a narrativa não se resolve.

Os personagens centrais são o pai e ela própria. Na história, é o pai que protagoniza as ações, Sofia muito mais sofre as ações do pai do que age no sentido de transformá-las. Lida com elas compreendendo-as, refletindo sobre elas, mas sem a competência para alterá-las. Não consegue transformar a situação de desequilíbrio inicial na narrativa, porém é capaz de transformar as situações de conflito em aprendizado. Sofia apresenta um caráter compassivo, que suporta e compreende as situações adversas, tentando extrair da família o que ela tem de melhor.

Na história de vida de Sofia há um contraponto entre a expressão de emoções e as de cognições. É recorrente a expressão de sofrimento seguida da consideração de que está tudo bem. No segundo episódio ela relata que a relação com o pai é boa, mas em seguida apresenta uma fala na qual não menciona um cuidado paterno no momento de uma cirurgia. No terceiro episódio, Sofia chora, fica muito triste e decepcionada com o pai, mas termina dizendo que a relação deles é tranqüila. No quarto episódio, após mencionar que o pai paga a pensão alimentícia somente quando processado, diz que está tudo bem. Sofia utiliza as expressões cognitivas para minimizar os afetos negativos e o sofrimento diante da falta da presença do pai na vida dela. Não vemos, portanto, uma expressão emocional genuína por parte de Sofia, mas uma racionalização. Ela ainda não consegue lidar com o conflito com o pai, mas aprende com ele e percebe a inadequação da maneira como a família lida com suas diferenças, através de brigas que não levam a sua resolução. O nó da narrativa permanece atado.

O não conseguir resolver a situação conflituosa não aponta, em um primeiro momento, para uma atitude resiliente, entretanto Sofia está em processo de aprendizagem a partir dos conflitos. Sua atitude reflexiva aponta para um processo de 
construção de uma identidade narrativa resiliente, o que se concretizaria no momento em que ela conseguisse protagonizar as ações de sua própria história de vida, reagindo de forma positiva em relação às situações adversas.

\section{Caso Antônio}

Antônio é um rapaz de 16 anos de idade que cursa o nono ano do ensino fundamental. Seus pais se separaram recentemente, tendo sua mãe deixado a casa a menos de um ano. Antônio e seus sete irmãos ficaram sob os cuidados do "pai", entretanto, em meio ao processo de separação, descobriu que a pessoa a quem tinha por pai não era seu pai biológico. Construiu uma narrativa biográfica em três episódios, enfocando questões de grande importância em sua vida: a separação do padrasto e da mãe e o abandono da mãe, a descoberta do pai biológico e o projeto de ser um bom rapaz.

No primeiro episódio, Antônio conta que seus pais se separaram duas vezes. A primeira separação ocorreu dois anos antes da nossa entrevista e a segunda separação há poucos meses atrás. Conta que conseguiu lidar melhor com a primeira separação, mas que no segundo rompimento "sentiu um baque" (Antônio, 16 anos). A mãe saiu de casa dizendo que dessa vez o rompimento era definitivo, deixando os oito filhos sob os cuidados do padrasto. Ao sair, falou que após o término do ano escolar, quem dos filhos quisesse poderia ir morar com ela. Antônio expressa seu sentimento com essa saída: "Mas é ruim né, viver sem a mãe. Bah, é a pior coisa" (Antônio, 16 anos). Termina esse episódio com uma reflexão sobre a dificuldade que os pais tiveram para se sustentar e criar os filhos, que os pais passaram fome e que batalharam muito para conquistar o que possuíam.

O segundo episódio introduz a descoberta de que o "pai" de Antônio não é seu pai biológico. Antes da segunda separação, descobriu através de uma mensagem enviada através do Whatsapp pela irmã, a notícia sobre o pai biológico. Ao confrontar a mãe, ela ficou zangada com isso, mas confirmou a paternidade, afirmando que ele era muito novo para saber e que iria contar-lhe tudo um dia, mas não agora. Em meio à discussão, disse que o padrasto não queria que Antônio soubesse da existência do pai biológico, pois foi ele quem o criou. A mãe ficou preocupada que o padrasto soubesse da revelação e a culpasse por ter falado. "Mas meu pai não sabe de nada ainda, ele acha que eu não sei de nada. Eu tenho vontade de falar, mas dai a mãe me disse: se tu abrir o jogo ele vai me culpar, de eu ter falado, que ele falou pra ela que não era pra ter falado" (Antônio, 16 anos).

No terceiro episódio, Antônio fala de seus planos para o futuro. Conta que está procurando estágio e que aguarda o retorno de uma seleção para vaga nos Correios. Está cursando o último ano do Ensino Fundamental e pretende continuar os estudos até onde lhe for possível. Ressalta que o padrasto tem um papel de incentivador em função de não ter tido a oportunidade de estudar. "Aí ele me incentiva muito a estudar, a trabalhar e ter meus bens e ser um guri bom" (Antônio, 16 anos). Antônio toma a narrativa do padrasto como referência para a construção de uma identidade e como projeto de vida. "Eu tento ser né, estudo, ajudo ele, ajudo minha mãe, cuido dos meus irmãos (...) e assim nós vamos levando a vida" (Antônio, 16 anos).

Antônio encerra a narrativa com uma avaliação que organiza sua experiência e constrói um significado acerca de seu projeto de vida. "A infância foi boa, brinquei bastante, agitei bastante, briguei bastante também. No colégio agitava muito, fazia tudo que eи queria, que nem o meu pai dizia: aproveita tudo que tu tiver que aproveitar agora, porque depois que tu tiver 18 anos, tu vai ter que ter uma vida que nem a do pai. Trabalhar, ter os meus negócios" (Antônio, 16 anos). Antônio toma a história de vida do padrasto como modelo identificatório de superação das dificuldades e tristezas que a vida lhe impõe. O estudo e o trabalho são percebidos como um caminho para a maturidade e para ser um guri bom.

Analisando a construção da estrutura narrativa de Antônio, verificamos que ele organiza os eventos relatando em primeiro lugar os emocionalmente mais carregados em detrimento da ordem cronológica. Isto é um indício de que Antônio passa por um momento de vida conflituoso, pleno de afetos (Vieira \& Henriques, 2013). A saída de casa por parte da mãe é 
sentida como um abandono. Além disso, a descoberta do pai biológico se constrói como um segredo, no momento em que Antônio não conversa com o padrasto. Essas duas situações dolorosas e não resolvidas configuram-se como nós na narrativa de vida de Antônio.

A narrativa de Antônio transcorre tendo como cenário o ambiente familiar. Os personagens são ele, o padrasto, a mãe e uma irmã. Antônio tem um papel ativo na história, ele cuida dos irmãos, ajuda o padrasto a escrever, investiga a paternidade, discute com a mãe, estuda e busca um estágio. Relata sentir-se triste com o afastamento com a mãe, chocado com a descoberta do pai biológico e tocado com o sofrimento dos pais. Sente-se sobrecarregado com tantos eventos carregados afetivamente, mas lida com eles contrapondo um projeto de vida focado na importância dos estudos e do trabalho. O padrasto aparece como o esteio desse projeto como modelo de posicionamento diante das dificuldades impostas pela vida com o qual Antônio se identifica. É esse modelo que possibilita a Antônio ressignificar as dificuldades e ir "levando a vida" (Antônio, 16 anos). Apesar de verificarmos que este projeto de vida auxilia Antônio na construção de uma identidade narrativa resiliente, as questões do abandono da mãe e a do surgimento do pai biológico ainda aparecem não resolvidas. São nós narrativos que necessitam ser desatados.

\section{Caso Catarina}

Catarina é uma jovem de 16 anos, cursando o nono ano do ensino fundamental. Conta que sua gravidez foi desejada, que é filha única de um casal que se divorciou quando ela tinha sete anos de idade, que presenciou as brigas e que isso a marcou. Catarina construiu uma narrativa em quatro episódios, iniciando sua história de vida no quinto ano do ensino fundamental, período em que sua avó se suicidou e no qual ela própria tentou se matar. Os temas dos episódios enfocam o suicídio da nona, bullying na escola, como comecei a me cortar e a retomada da relação com a mãe.

No primeiro episódio, Catarina narra que quando estava no quinto ano do ensino fundamental sua avó se suicidou jogando-se na frente de um trem. Era a avó quem cuidava dela e Catarina a tinha como uma mãe. Conta que sentiu-se abandonada, que ficou abalada e depressiva, tendo repetido duas vezes o quinto ano. Contou que sua mãe a deixava sozinha porque corria atrás de seu pai biológico. "Isso foi horrível, tanto que eu desandei. Sei lá tipo, pelo o que todos falavam eu realmente, eи me superei, porque todos diziam que eи ia acabar virando, como eles falam: vagabundinha, ou uma drogada, viciada" (Catarina, 16 anos). Mas conta que isso não aconteceu, que nunca usou drogas, que continuou a estudar e a fazer cursos. "Sempre tentando dar a volta por cima, mas isso me marcou por muitos anos, tanto que eu ainda tô superando isso. Foi a coisa mais importante da minha vida até agora" (Catarina, 16 anos). Termina o episódio dizendo que hoje já não é mais tão difícil falar sobre o suicídio da avó, mas que ainda está superando isso. Em relação à mãe, conta que ela retomou o lugar de mãe, que agora é mais presente e que as duas superaram isso juntas. Encerra declarando-se ateia.

No segundo episódio introduz o tema da escola. Começa dizendo que sempre gostou de ficar sozinha, que tem dificuldades em se "enturmar" e que é o primeiro ano que sabe o nome de todos os colegas. Falou que desde que entrou na escola, com 6 ou 7 anos de idade, sofreu bullying. Acredita que sofria bullying por ser "feinha", e acrescenta que ainda hoje considera-se feia. No recreio roubavam o dinheiro de seu lanche e batiam nela. Quem a agredia era o filho da diretora, de maneira que quando reclamou à direção da escola, nada mudou. Catarina então começou a praticar Taekwondo e Muay Thai, e em uma das vezes que foi molestada deu uma surra no agressor. Conta que sua mãe foi processada por causa disso, mas que valeu a pena, senão ela continuaria sendo perseguida. A partir desse evento, o bullying cessou. Finaliza esse episódio contando que sente-se deslocada e diferente dos outros adolescentes, enfatizando o quanto isso é difícil. Diz que gosta de sair à noite para ouvir rock ou música eletrônica e conversar com os amigos, mas que a maioria das pessoas vai às festas só para "pegação". "Muita vulgaridade e isso me afasta, e isso é a maioria dos adolescentes da minha idade" (Catarina , 16 anos). Segundo Catarina, esse sentimento de ser diferente é partilhado por outros adolescentes. "Tem gente que me chama de diversas 
coisas, já falaram até que eu fiz pacto com o capeta, super lógico uma ateia. Por usar preto, por curtir rock. Rock é do demônio, não é? Quero ver se Jesus canta funk" (Catarina, 16 anos).

Inicia o terceiro episódio dizendo que sente-se deslocada em relação aos outros jovens de sua idade. Conta que na época em que sua avó se suicidou, teve depressão e se cortava. "Comecei a me cortar por ver os outros fazendo, que os outros falavam que era bom, que aliviava e realmente alivia, era o único jeito que eu não chorava" (Catarina, 16 anos). Então passou a se cortar por qualquer motivo, brigas familiares ou notas baixas na escola. "Qualquer coisa que acontecia eu me cortava, ah, minha mãe brigava comigo por um motivo besta ou nota baixa, ou coisas assim bestas, mas parei porque quis parar" (Catarina, 16 anos). Naquele momento sentia-se perdida, foi então que tentou se matar. Conta que cortou o pulso mais fundo, mas errou a veia, e que felizmente não precisou ir ao hospital. Este foi para ela um ponto de viragem. Segue dizendo que é forte, que superou as dificuldades da vida praticamente sozinha, mas que naquela hora difícil um amigo a ajudou. "Eu devo muita coisa a meи amigo. Ele evitou que eu fizesse muita coisa. Ele está comigo até hoje. Todo fim de semana saindo, ele sempre comigo. É sempre muito bom termos um amigo fiel pra confiar" (Catarina, 16 anos).

Inicia o quarto episódio dizendo que hoje a mãe é sua melhor amiga. Conta que depende financeiramente da mãe, mas esta tem uma dependência afetiva muito grande da filha. "Eu sou realmente a única pessoa que ela pode contar e confiar" (Catarina, 16 anos). Fala que fica feliz por essa dependência porque sente-se valorizada e cuidada pela mãe, mas triste pela mãe não poder confiar em si mesma. Conta que sua mãe é apaixonada pelo padrasto, mas que eles brigam muito, falam coisas sem pensar e se machucam. "Não devia ser assim, ela devia pensar antes de falar, todos nós somos assim, machucamos quem nós amamos. Eu já machuquei muita gente também e agora eu procuro me controlar" (Catarina, 16 anos). Fala que ela própria gosta muito do padrasto, que ele substituiu seu pai, e encerra a entrevista perguntando jocosamente se é normal e relatando um incipiente projeto de futuro ao dizer que gosta de estudar o corpo e seus órgãos.

Analisando a construção da estrutura narrativa da história de vida de Catarina, observamos que, após uma breve orientação geral, ela inicia o primeiro episódio com uma situação do passado recente intensamente carregada de afeto, o suicídio da avó, e o impacto que isto teve em sua vida. Após esse episódio ela fala da entrada na escola e de outra situação afetivamente carregada, o bullying. No terceiro episódio, retorna temporalmente ao momento do suicídio da avó, encerrando sua história no quarto episódio, no qual fala de seu momento de vida atual. O terceiro episódio é uma retomada do primeiro e o encaminhamento de uma solução para os problemas levantados naquele momento crítico de sua vida, a dissolução da família com a morte da avó e o distanciamento da mãe. Essa alteração na ordem cronológica da narração segue a lógica dos eventos afetivamente mais carregados. Estes são contados em primeiro lugar, mas nunca abordados completamente em um único episódio (Vieira \& Henriques, 2013). O narrador retorna a eles mais adiante na história, complementando-os com elementos afetivos mais intensos e difíceis de falar. É o que acontece em relação ao episódio do suicídio da avó, que só é fechado após a recuperação de Catarina em relação à própria tentativa de suicídio. O mesmo pode ser dito em relação ao distanciamento da mãe, que só vai ser resolvido no episodio final da narrativa, com a retomada da relação com a mãe e a reorganização familiar, na qual ela sente-se acolhida e vê suprida sua necessidade de afeto.

O suicídio da avó e o espelhamento disso em sua tentativa de suicídio aparecem como um nó ainda não resolvido, ao passo que a relação com a mãe é um nó desatado com a retomada da relação mãe-filha. Outro nó não resolvido na narrativa de Catarina é o sentimento de que é diferente em relação aos outros jovens. Essa questão aparece desde o início até o final da história. O ser diferente, seja pelo sofrimento com o suicídio da avó, o distanciamento da mãe, o ser ateia, a própria tentativa de suicídio, o sofrer bullying, o não gostar das práticas sexuais dos pares e o olhar destes, que a vêem como diferente, é uma característica marcante da identidade narrativa de Catarina.

Enquanto protagonista, nos três primeiros episódios, Catarina encontra-se em uma situação de vulnerabilidade provocada por eventos externos a ela: o suicídio da avó, o distanciamento da mãe e o bullying na escola. Esses eventos 
provocam uma desorganização: fica depressiva, reprova no quinto ano, corta-se, tenta se matar. Entretanto, após um período de abatimento, Catarina reage e supera as dificuldades: busca apoio afetivo em um amigo, retoma os estudos, para de se cortar, apóia a mãe, aprende a lutar e enfrenta o agressor. Catarina constrói uma identidade narrativa retratando-se como uma pessoa que sofre uma ação opressiva, que se abate por isso e fica vulnerável, mas que reage, retomando com o próprio esforço o controle da situação no sentido de procurar ficar bem, em uma trajetória redentiva e de autoconstrução. Neste sentido, Catarina mostra um posicionamento intelectual e afetivo, a partir do qual ela afirma suas escolhas e o que pensa em relação aos outros e à vida.

A análise do processo narrativo mostra a história de Catarina com muitas reflexões e expressões de sentimento. A maioria dos sentimentos relatados são de tristeza e sofrimento pelas situações vividas, aparecendo também uma autodepreciação, ao se definir como feia. A tonalidade emocional muda quando fala do amigo, acerca de quem diz que "é sempre muito bom termos um amigo fiel pra confiar" (Catarina, 16 anos). Fala também da alegria a respeito da relação com a mãe. Fica feliz que a mãe precise dela, porque assim a mãe cuida dela. Por outro lado, fica triste porque a mãe precisa dela, porque a mãe tem só a ela e não pode confiar em si. Os sentimentos de tristeza e de alegria aparecem associados a uma necessidade de vinculação afetiva. Catarina busca fundamentalmente uma vinculação afetiva com a mãe e com a família.

As expressões de pensamento de Catarina têm em geral um caráter afirmativo de si. É muito significativa a fala: " $E u$ sempre tive o pensamento muito forte, superei todas as minhas coisas praticamente sozinha" (Catarina, 16 anos). Isso se repete quando ela se define como atéia porque acredita apenas no que vê, sente ou ouve, quando afirma que gosta de ficar sozinha, quando critica a postura dos pares em relação à sexualidade, quando reflete sobre a passionalidade da relação amorosa da mãe com o padrasto ou quando se vê como muito diferente das outras pessoas, uma "extraterrestre", alguém que não é normal. Esta postura reflexiva, racional e focada na individualidade é também uma marca característica de sua identidade narrativa.

\section{Discussão}

\section{The Big Three e as Diferentes Formas se Reorganizar Frente ao Sofrimento}

As histórias de vida de Sofia, Antônio e Catarina mostram diferentes maneiras de lidar com o sofrimento e de buscar superação das dificuldades apresentadas pela vida. As histórias mostram diferentes situações disruptivas e diferentes personalidades que, reagindo aos eventos conflituosos, constroem formas diferentes de lidar. Essa diversidade, que corresponde à complexidade e variedade da forma humana de ser, é abarcada pelo trabalho de McLean et al. (2019). A construção narrativa de bem-estar em meio às dificuldades só pode ser verificada a partir de um entrelaçamento de múltiplas dimensões, ao mesmo tempo do discurso e da personalidade. Linguagem e identidade aparecem aqui unidas em nossa forma de pensar, sentir e agir. No caso, as referidas dimensões são a organização estrutural do discurso narrativo, a reflexão sobre si mesmo e o caráter dos temas afetivos e motivacionais presentes na narrativa. Nas histórias de vida aqui discutidas vemos a alternância de ênfase entre estas dimensões, cada qual correspondendo a um estilo de personalidade e a uma forma particular de enfrentamento das dificuldades. Vejamos a seguir os nossos narradores.

Tanto Sofia, como Antônio e Catarina enfrentaram situações dolorosas que marcaram sua trajetória de vida. Essa marca aparece na forma de organizar as suas histórias: a estrutura narrativa. Não encontraremos nelas uma narração cronológica, a partir do nascimento, que venha avançando linearmente e contando-nos os eventos mais significativos. Ao contrário, todos começam sua história no momento traumático que mudou o rumo de suas vidas e que exigiu deles uma nova reorganização. No caso de Sofia foi a ruptura com o pai após a separação da família, no de Antônio, o abandono por parte da mãe, e no de Catarina, o suicídio da avó. Esta forma de organização narrativa foi relatada por Vieira (2012) e Vieira e Henriques (2013) em estudos com jovens adotados. Os jovens adotados tardiamente que tinham experienciado situação de 
negligência ou maus tratos por parte dos pais biológicos, bem como aqueles que tinham enfrentado alguma forma de enfermidade ao longo do processo de desenvolvimento, narraram sua história de vida tendo como referência o evento traumático. Esta quebra na organização cronológica da estrutura narrativa é indício da presença de um afeto potencialmente desorganizador da personalidade, oriundo de uma questão pessoal não resolvida (Gedrat, Vieira \& Schubert, 2019; Henriques, Vieira \& Gedrat, 2021). É interessante destacar esta questão não resolvida a partir da leitura de Jung (1984) da Poética de Aristóteles: ela passa a ser entendida como um nó narrativo que necessita ser desatado e como um complexo de tonalidade afetiva a ser conscientizado e resolvido. Entretanto, as narrativas construídas por Sofia, Antônio e Catarina não se apresentam desestruturadas, todas elas possuem uma coerência lógica e contextual, o que aparece na inteligibilidade com a qual os fatos são narrados. Esta coerência é um indício da capacidade desses jovens de lidar com as experiências traumáticas, mesmo que ainda não tenham conseguido integrá-las (Habermas \& de Silveira, 2008; McLean et al., 2019).

Em relação ao autobiographical reasoning (McLean et al., 2019), encontramos nos três casos uma postura reflexiva em relação a sua própria história, que aparece em uma visão crítica das ações da família. Essa crítica aparece como transformação das situações difíceis em aprendizado e se constitui como um elemento fundamental na planificação de um projeto de vida para o presente e futuro. Em Sofia, a falta de uma conexão com os afetos dolorosos produz uma visão menos crítica em relação ao pai. Ela sistematicamente evita o confronto com os sentimentos de decepção vivenciados em relação a ele. Isso produz uma narrativa de reflexão assimilativa, cujo tema é a expectativa de harmonização das pessoas em um relacionamento pacífico. Por mais que isso esteja em desacordo com as situações trazidas por ela, se mantém como uma narrativa e como um projeto de vida até o final da narração de sua história, incorporando a ele seu principal problema, nomeadamente, as brigas de família provocadas pelo pai. Isso já não acontece com Antônio ou com Catarina. Antônio vivencia situações disruptivas dolorosas: a separação dos pais, o afastamento da mãe e a descoberta de que não é filho biológico da pessoa que tem como pai. Ele vivencia a dor dessas perdas, se acomoda à impossibilidade de ter algum controle sobre estas situações e segue sua história de vida construindo uma narrativa focada nele como protagonista. Nesta narrativa ele assume o controle sobre a própria vida em um projeto já em andamento, no qual ele percorre o caminho de ser um adulto responsável e trabalhador. Trata-se de uma reflexão acomodativa, já que cria uma nova narrativa de um novo Antônio que sai da infância para a adultez. A narrativa de Catarina segue um caminho semelhante à de Antônio. O momento traumático do suicido da avó e do conseqüente desmembramento familiar junto ao momento de adolescência exige dela a construção de uma nova identidade narrativa. A nova narrativa vai sendo construída a partir do momento de crise, em que ela se sente perdida. Este momento crítico aparece nela repetidamente como um episódio que antecede uma acomodação adaptativa à nova situação de vida. Ele é seguido por um ponto de viragem, no qual a nova narrativa começa a ser escrita. Tanto em Antônio como em Catarina a nova narrativa que segue ao episódio de vida disruptivo/traumático é focada no próprio protagonismo. Aqui a reflexão é seguida pela ação, reforçando o caráter motivacional da narrativa.

Quanto à organização dos temas afetivos e motivacionais (McLean et al., 2019) temos as histórias de vida de Antônio e Catarina fortemente centradas no sentido da auto-afirmação. Em ambas, os autores relatam a tomada de controle sobre suas próprias vidas após período de grandes dificuldades, construindo narrativas de agenciamento e redenção. Catarina parece sofrer as dificuldades de forma mais intensa. Ela relata situações em que ela se desorganiza profundamente ou em que se mostra impotente diante de um agressor, mas sua reação é surpreendentemente potente e transformadora. Já Antônio parece tirar sua força do amor pelo pai e pelo projeto do pai para Antônio: ser uma pessoa boa e trabalhadora. $\mathrm{O}$ anseio de comunhão com as pessoas amadas se entrelaça com o de auto-afirmação, sendo ambos poderosos agentes motivadores da narrativa. No caso de Catarina, isso aparece no anseio dela ser o apoio da mãe. Na história de Sofia não encontramos esse protagonismo. A motivação dela está em construir paz e harmonia em sua própria família. Sua narrativa está fortemente focada em um projeto de comunhão entre seus familiares e ela tenta organizar sua vida em torno desse projeto. Como o sucesso não depende 
exclusivamente dela, Sofia tem de preencher as lacunas contornando as recorrentes situações de conflito e evitando sentimentos oriundos do fracasso das relações familiares. Por isso é difícil identificar uma tonalidade afetiva objetiva em sua narrativa, embora se espere sentimentos de pessimismo e tristeza. A história de Sofia contrasta também neste sentido com a de Catarina e a de Antônio, nestas, apesar da tristeza, há um forte sentimento de otimismo e autoconfiança. Essa lacuna na capacidade de agenciamento de Sofia parece estar relacionada à falta de resolução dos problemas. A história de Sofia apresenta-se como uma narrativa cujos nós não são desatados e que, portanto, não se resolve (Jung, 1984).

\section{Considerações Finais}

Sofia, Antônio e Catarina trazem histórias de vida singulares, nas quais os elementos da narrativa se entrelaçam em um jogo, no qual se complementam nas tentativas dos narradores em construir sentido às próprias experiências e equilíbrio em suas personalidades. Assim, vimos aqui a coerência lógica compensar a falta de coerência cronológica, quando as situações afetivas são demasiadamente prementes para serem narradas após episódios de vida menos importantes. No autobiographical reasoning, vimos o papel transformador da visão crítica em relação à própria família, e o quanto a falta desta provoca um distanciamento da realidade em narrativas exclusivamente assimilativas que dificultam o processo de transformação das dificuldades impostas pela vida em aprendizagem e transformação. Finalmente, em relação aos temas afetivos e motivacionais vimos a importância do protagonismo na capacidade de agenciamento das situações adversas. Nas histórias de Sofia, Antônio e Catarina, agenciamento e comunhão apareceram como tendências afetivo-motivacionais que se entrelaçaram nas necessidades de amor (e reconhecimento) e de ação organizadora da própria vida. A tonalidade afetiva das histórias nos pareceu estar diretamente relacionada à capacidade de agenciamento, mas também à capacidade de tecer uma rede de relações afetivas. Assim, as situações de vida com as quais nossos autores não conseguiram lidar (os nós não desatados) foram fontes de tristezas e potencialmente perturbadores da organização da narrativa e da personalidade.

A abordagem narrativa da identidade que aqui apresentamos aparece como um contributo ao estudo da construção do sujeito psicológico através da linguagem. Seguindo os passos de Vygotsky (1993), Wittgenstein (1979) e Bruner (1987), tomamos o conceito de linguagem como um sistema vivo, aberto, histórica e culturalmente situado que nos constrói, ao mesmo tempo em que é por nós construído. A construção narrativa de histórias de vida como construção desse aspecto da personalidade que chamamos identidade é a aplicação desse conceito de linguagem à psicologia. Enquanto seres de linguagem, somos construídos através de nossa história e da história daqueles que nos cercam, assim como através de todos os conceitos e preconceitos que nossa cultura carrega. Certamente podemos sempre nos contrapor a eles e mesmo construir novos conceitos e valores culturais, mas como bíos politikos que somos, jamais poderemos nos furtar de encarar e confrontar o mundo que nos cerca. Disso depende nossa organização como sujeitos, bem como da nossa identidade e personalidade. Para estudos futuros, fica o desafio da continuidade da investigação em torno da construção psicológica, histórica e cultural do sujeito psicológico.

\section{Referências}

Adler, J. M., Lodi-Smith, J., Philippe, F. L., \& Houle, I. (2016). The incremental validity of narrative identity in predicting well-being: A review of the field and recommendations for the future. Personality and Social Psychology Review, 20(2), 142-175. http://dx.doi.org/10.1177/1088868315585068

Bruner, J. (1987). Life as narrative. Social research, 54 (1), 11-32.

Bruner, J. (1991). The narrative construction of reality. Critical Inquiry, 18, 1-21.

Fivush, R. (2008). Remembering and reminiscing: How individual lives are constructed in family narratives. Memory Studies, 1 (1), $49-58$.

Fitzhardinge, H. (2008). Adoption, resilience and the importance of stories. Adoption and Fostering, 32 (1), 58-68.

Gedrat, D. C., Vieira, A. G., \& Schubert, C. (2019). Coherence and awareness among young people from quilombo do areal. English Linguistics Research, 8 (4), 18-26. 
Gonçalves, O. F., Henriques, M. R. \& Cardoso, G. (2006a). Sistema de avaliação da matriz narrativa: Coerência estrutural narrativa. Braga: Departamento de Psicologia da Universidade do Minho.

Gonçalves, O. F., Henriques, M. R., Alves, A. \& Rocha, C. (2006b). Sistema de avaliação da matriz narrativa: Complexidade do processo narrativo. Braga: Departamento de Psicologia da Universidade do Minho.

Gonçalves, O. F., Henriques, M. R., Soares, L. \& Monteiro, A. (2006c). Sistema de avaliação da matriz narrativa: Diversidade de conteúdo narrativo. Braga: Departamento de Psicologia da Universidade do Minho.

Gonçalves, O. Henriques, M. R. \& Vieira, A. G. (2010). Entrevista de Elicitação de Narrativas de Vida. Porto: Faculdade de Psicologia e Ciências da Educação da Universidade do Porto.

Habermas, T. \& de Silveira, C. (2008). The development of global coherence in life narratives across adolescence: temporal, causal and thematic aspects. Developmental Psychology, 44, 707-721.

Habermas, T., Ehlert-Lerche, S., \& de Silveira, C. (2009). The development of the temporal macroestructure of life narratives across adolescence: Beginnings, linear narrative form, and endings. Journal of Personality, 77 (2), 527-559.

Henriques, M. R., Vieira, A. G., \& Gedrat, D. C. (2021). Construção e re-construção da identidade nas histórias de vida de adotados. Aletheia, 54 (1), 6-15.

Hermans, H. J. M., \& Kempen, H. J. G. (1993). Imaginal dialogues in the self: Theory and method. Journal of Personality, 61(2), 207-236.

Hermans, H. J. M. (2008). How to perform research on the basis of dialogical self theory? Introduction to special issue. Journal of Constructivist Psychology, $21,185-199$.

Jung, C. G. (1984). A dinâmica do inconsciente. Vozes.

László, J., Ehmann, B., Pólya, T., \& Péley, B. (2007). Narrative psychology as science. Empirical Text and Culture Research, 3 , 1-13.

McAdams, D. P. (2001). The psychology of life stories. Review of General Psychology, 5 (2), 100-122.

McAdams, D. P. \& McLean, K. C. (2013). Narrative identity. Current Directions on Psychological Science, 22 (3), $233-238$.

McLean, K. C., Pasupathi, M., \& Pals, J. L. (2007). Selves creating stories creating selves: A process model of self-development. Personality and Social Review, 11, 262-278.

McLean, K. C., Syed, M., Pasupathi, M., Adler, J. M., Dunlop, W. L., Drustrup, D., Fivush, R., Graci, M. E., Lilgendahl, J. P., Lodi-Smith, J., McAdams, D. P., \& McCoy, T. P. (2019). The Empirical Structure of Narrative Identity: The Initial Big Three. Journal of Personality and Social Psychology. Advance online publication. http://dx.doi.org/10.1037/pspp0000247

Sarbin, T. R. (1986). Narrative psychology: The storied nature of human conduct. Praeger Publishers/Greenwood Publishing Group.

Vieira, A. G. (2012). A construção narrativa da identidade em jovens adotados. Faculdade de Psicologia e Ciências da Educação da Universidade do Porto.

Vieira, A. G., \& Henriques, M. R. (2013). A construção narrativa da identidade em jovens adotados: o caso Beno. Análise Psicológica, 2 (XXXI), 145-157.

Vieira, A. G., \& Henriques, M. R. (2014) A construção narrativa da identidade. Psicologia: Reflexão e Crítica, 27 (1), $163-170$.

Vygotsky, L. S. (1993). Pensamento e linguagem. Martins Fontes.

Wittgenstein, L. (1979). Investigações filosóficas. Abril Cultural.

Yin, R. K. (2001). Estudo de caso: planejamento e métodos. Bookman. 